\title{
A Coordinated Control Approach for DC link and Rotor Crowbars to Improve Fault Ride-Through of DFIG-Based Wind Turbine
}

\author{
Ahmed M. A. Haidar, Senior Member, IEEE, Kashem M. Muttaqi, Senior Member, IEEE, \\ and Mehrdad Tarafdar Hagh, Senior Member, IEEE
}

\begin{abstract}
Nowadays, most double fed induction generators (DFIGs)-based wind turbines are equipped with a rotor crowbar connected in parallel with the rotor side converter (RSC). The parallel rotor side crowbar (PRSC) is used to protect the RSC and dc-link capacitor by dissipating the rotor energy during grid fault condition. In this paper, two types of crowbar protections are used, one in the rotor winding and the second in the dc link. During the fault condition, the rotor winding crowbar connects in series with the rotor winding and RSC to decrease the RSC current and dissipate the rotor energy. The general PRSC does not have the ability to significantly decrease the over-current. To protect the semiconductor switches of RSC, DFIG should not be kept connected with the utility grids under severe faults. The dc-link capacitor crowbar (DCCC) operates only if the dc capacitor voltage exceeds a threshold level. Both the series rotor side crowbar (SRSC) and the DCCC operate in coordination with each other to protect RSC and dc link during fault condition, and improve the fault ride through of the DFIG. Using the proposed SRSC, RSC continues its operation to control the DFIG during fault condition. Thereby, the reactive power can be injected to support the voltage at the point of common coupling. The behavior of the DFIG is investigated when the combined crowbars are operating with the proposed coordinated control approach and results are presented.
\end{abstract}

Index Terms-Crowbar protection, dc link, DFIG, low voltage ride-through (LVRT), parallel rotor crowbars, series rotor crowbar, vector control.

Manuscript received April 23, 2016; revised October 26, 2016 and February 3, 2017; accepted March 14, 2017. Date of publication March 22, 2017; date of current version July 15, 2017. Paper 2016-IACC-0360.R2, presented at the 2015 IEEE Industry Applications Society Annual Meeting, Addison, TX, USA, Oct. 18-22, and approved for publication in the IEEE TRANSACTIONS ON INDUSTRY APPLICATIONS by the Industrial Automation and Control Committee of the IEEE Industry Applications Society. (Corresponding author: Ahmed M. A. Haidar.)

A. M. A. Haidar is with the Department of Electrical and Electronic Engineering, Universiti Malaysia Sarawak, Samarahan 94300, Malaysia, and also with the School of Mechanical and Electrical Engineering University of Southern Queensland, Toowoomba, QLD 4350, Australia (e-mail: ahahmed@unimas.my).

K. M. Muttaqi is with the School of Electrical, Computer, and Telecommunications Engineering, University of Wollongong, Wollongong, NSW 2522, Australia (e-mail: kashem@uow.edu.au).

M. T. Hagh is with the Faculty of Electrical and Computer Engineering, University of Tabriz, Tabriz 51666, Iran, and also with the Engineering Faculty, Near East University, Mersin 99138, Turkey (e-mail: tarafdar@ tabrizu.ac.ir).

Color versions of one or more of the figures in this paper are available online at http://ieeexplore.ieee.org.

Digital Object Identifier 10.1109/TIA.2017.2686341

\section{INTRODUCTION}

A $\mathrm{S}$ THE number of wind turbines connected to the grid is continuously increasing, wind power will play a significant role in grid power in the future; this will require more wind turbines to stay in grid connected during a grid fault. The low voltage ride-through (LVRT) or fault ride-through (FRT) is a term used to describe the capability of wind energy conversion systems to contribute to the grid voltage control during grid faults which is critical for insuring power system stability. This is also an essential requirement of wind park grid code [1].

The variable speed wind turbines which are controlled through power electronic converters are widely used in the new wind farm installations. Thus, these types of wind turbines are able to regulate their own reactive power, so as to operate at unity power factor [2]-[6]. Nowadays, the most widely used generator type is the double fed induction generator (DFIG); the block diagram of a DFIG-based wind turbine is shown in Fig. 1. In this type, the stator windings are directly connected to the grid and the rotor windings are fed through bidirectional pulse-width modulation (PWM) voltage source converters. In other words, the machine is controlled via converters connected between the rotor and the power grid. The converters are designed to transfer a part (about 30\%) of the full power of the machine [1], [4], [5]. The size of these converters determines the speed range of the DFIG. The rotor side converter (RSC) controls the wind turbine active and reactive powers from stator to grid. The grid side converter (GSC) controls the dc-link voltage and allows the converter to generate or absorb reactive power [6]. The stator and rotor of DFIG are able to supply the power. However, the direction of active power flow through the rotor circuit depends on the wind speed and hence the generator speed [7]. The main disadvantage of the DFIG is its sensitivity to power grid disturbance as the DFIG is directly connected to the grid through the stator winding [8].

To improve the fault handling capacity and protect the DFIG converter from high rotor current during grid faults, a crowbar is usually adopted in order to limit the high currents and voltages in the rotor circuit, where the back-to-back power converter is used. The behavior of DFIG was investigated in [9], when an active crowbar is used to provide low-voltage ride through capability by short-circuiting the rotor temporarily. It was found that DFIG allows the reactive support to the power grid even 